\title{
The Evolution of the International Business Field: A Scientometric Investigation of Articles Published in its Premier Journal
}

\author{
Peter W. Liesch • Lars Ha ${ }^{\circ}$ kanson • Sara L. McGaughey • Stuart Middleton • Julia Cretchley
}

\begin{abstract}
Macro-environmental trends such as technological changes, declining trade and investment barriers, and globalizing forces impacting both markets and production worldwide point to the heightened importance of international business (IB) and the relevance of IB research today. Despite this, a leading scholar has expressed concerns that the IB research agenda could be 'running out of steam' (Buckley 2002), prompting on-going introspection within the IB field. We contribute to this debate by investigating the evolution of the IB field through a scientometric examination of articles published in its premier journal, the Journal of International Business Studies (JIBS) from 1970 until 2008. We introduce a new analytical tool, Leximancer, to the fields of international business and scientometry. We show an evolution from an initial and extended emphasis on macro-environmental issues to a more recent focus on micro-economic, firmlevel ones with the multinational enterprise (MNE) as an organizational form enduring throughout the entire period. We observe a field that has established a justifiable claim for relevance, participating actively in the interdisciplinary exchange of ideas.
\end{abstract}

Key words: International business, scholarly field, evolution, concepts, Leximancer.

P. W. Liesch (\&)__L. Ha*kanson__S. Middleton

UQ Business School, The University of Queensland, St. Lucia, QLD 4072, Australia

p.liesch@uq.edu.au

I.hakanson@business.uq.edu.au

s.middleton@uq.edu.au

L. Ha ${ }^{\circ}$ kanson

Department of International Economics and Management, Copenhagen Business School, Copenhagen, Denmark

S. L. McGaughey

University of Strathclyde Business School, 199 Cathedral Street, Glasgow G4 0QU, UK

sara.mcgaughey@gsb.strath.ac.uk

J. Cretchley

Leximancer Pty. Ltd, Jindalee, QLD 4074, Australia

julia@leximancer.com 


\section{INTRODUCTION}

As the official journal of the Academy of International Business, the Journal of International Business Studies (JIBS) is the premier journal in the field of international business (IB) and has remained so since it published its first issue in 1970. In the suite of IB journals, it has records the highest Impact Factor consistently (Garfield 1998, Journal of International Business Studies 2011). The field of IB, as recorded in $J I B S$, covers a diverse range of topics, befitting of a scholarly domain which examines fundamental issues of modern day business activity that crosses national borders, conducted by firms with interests in both home and host countries. At this time, and with macro-conditions throughout the world favoring the increased internationalization of business activity, it is perplexing that the question could be posed of the IB research agenda that it could be 'running out of steam' (Buckley 2002). What leads an eminent scholar in the field to ask whether its research agenda is running out of steam when the broad fundamentals of the world economy, and their ever-changing effects, signal a prescient need to better understand how international business is conducted and how it impacts the environment locally and globally? We contribute to this discussion, addressing the question: How has the field of international business evolved, as reflected in articles published in its premier journal, the Journal of International Business Studies?

Reflection on the evolution of IB is not a new phenomenon. Scholars in the field have periodically analyzed and commented upon its status, aims, achievements, relevance and future directions (Table 1). This is encouraging and constructive for a young and expanding field with wide and challenging opportunities to unearth new agendas ensuing from the increasing and ever-changing importance of crossborder business activity. However, throughout the field's history, even the most constructive criticism has often had the undertone of questioning its relevance and, sometimes, its very raison d'être. Recently, for example, Buckley and Lessard (2005: 598) implored IB researchers "to find ways of making their own (discipline-based) approaches accessible to others operating in the community [of IB], and their phenomenological observations relevant across disciplines". They question the relevance, quality and influence of IB research and implicitly invite the IB community to substantiate their claim for this scholarly domain, and to maintain its currency through a positive balance of exchange in ideas. 
Responding to this challenge, we rely not on personal memory and recollection, nor on conjecture, but on data, recorded as scholarly articles to scientometrically analyze the field's evolution. Our study is novel to the IB field, although scientometric analysis was first employed by Hofer and colleagues in a recent, but more limited, study of Academy of International Business conference proceedings for the three years 2006-2008 (Hofer, Smejkal, Bilgin and Wuehrer 2010). Complementing this pioneering contribution, our study analyzes the development of the scientific domain almost from its inception, covering four decades of international business research. The paper proceeds as follows. First, we contextualize our analysis by examining earlier articles in JIBS that reflect on the state and direction of international business research. We then introduce our analytical tool to the field of scientometry and explain the logic of the Leximancer software employed and the nature of the information it generates. This leads to our analysis which is organized around the main research themes that have evolved from the inception of JIBS, through six editorships to the present. An overview of the entire period introduces this analysis. Discussion follows with concluding remarks.

\section{CRITIQUE OF THE INTERNATIONAL BUSINESS FIELD}

A notable feature of IB as a field of academic inquiry has been the willingness of its scholars to engage in introspection and to question its conceptual and empirical domain, the methods used and the relevance of their collective endeavors. In the inaugural issue of Journal of International Business Studies, Wright (1970) outlined the scope and state of IB research based on a review of over 300 completed and 111 ongoing projects, and, drawing on the opinion of 30 industry and academic experts from a variety of disciplines and functions, proposed future areas of investigation. Over the subsequent four decades, the tradition of introspection has remained strong and is regularly recorded by the publication of empirical articles, thought pieces and AIB presidential addresses in JIBS, discussing the evolution of IB as a discipline and requirements for its further advancement (see Table 1).

\section{INSERT TABLE 1 ABOUT HERE}

A review of the publications listed in Table 1 identifies a number of consistencies over time in the discipline's evolution, as well as some seeming contradictions and ambiguities. For example, Wright 
(1970:112) identified in the late 1960s a "dramatic focusing of current research into broader problems of international business strategy and structure that transcend the traditional functional lines of research". Later, Arpan, Flowers and Ricks (1981) lamented the absence of functionally-oriented studies, while subsequently, others (e.g., Wright and Ricks 1994, Toyne and Nigh 1998, Sullivan 1998) despaired at the dominance of a narrow functional focus in much IB research. Interest in the macro-environment and the role of government, for example, entered early in the field's evolution, with Wright (1970) calling for linkages to be drawn between the macro-environment and firm-level business activity. Related is the apparent continuing dominance of US-centric studies (Thomas, Shenkar and Clark 1994), despite early observations that more European scholars were engaging with IB research (Wright 1970) and of an increasing diversity in the geographic location of IB research activity (Wright and Ricks 1994). Several reviews expressed a sense of déjà $v u$ in IB research, with suggestions that there is too much reinventing of the wheel (Dymsza 1984, Daniels 1991, Sullivan 1998), while others point to ever-burgeoning diversity (e.g., Wright and Ricks 1994, Griffith, Cavusgil and Xu 2008).

Perceptions of a functional (if not geographic) dominance that was too narrow and a lack of novelty are reflected in calls for greater interdisciplinarity. Terpstra (1973), for example, early on called for more interdisciplinary collaborations between scholars in IB and non-business fields - a call later echoed and elaborated by Dymsza (1984) ${ }^{1}$, Dunning (1989), Wright and Ricks (1994), Shenkar (2004) and Sullivan and Daniels (2008), among others. Shenkar (2004) observed, however, that many calls for interdisciplinarity limit themselves to the business disciplines, a point also reflected in empirical assessments of disciplinary influences (e.g., Chandy and Williams 1994, Inkpen and Beamish 1984), and he deplored the more recent "convergence and imitation" by IB scholars of the "simplistic tools used by strategy" which are "illequipped to handle the challenges of the global economy" (Shenkar 2004: 167). Growing methodological sophistication and rigor had been observed, applauded or advocated as essential to establishing credibility and to progress the discipline (Wright 1970, Buckley 2002). Other commentators have suggested that the increasingly 'sophisticated' quantitative methods and narrow paradigmatic thinking privilege method above ideas and preclude the understanding of interrelationships across levels within the rich empirical contexts

\footnotetext{
${ }^{1}$ Dymsza uses multidisciplinary and interdisciplinary interchangeably. Distinctions between the meaning of multidisciplinary and interdisciplinary are not always clear.
} 
that are a defining characteristic of IB scholarship (Shenkar 2004, Sullivan 1998, Sullivan and Daniels 2008).

The early IB studies were primarily descriptive, as scholars set out to survey their field - the activities of MNEs at home and abroad. As early as 1983, Lessard, Wells and Brandt recognized the role of 'positive and normative studies' and studies of processes. Sekaran (1983) saw the need to progress toward a solid theoretical base, and a steady stream of scholars speculated on method, such as Dymsza (1984) and Hawkins (1984) seeking 'synthesis' and calling for a 'unifying paradigm', with Ricks (1985) wanting more 'integrative' theory-building work while not neglecting empirical research as its base. Daniels (1991) called for 'theory' and new-ideas ‘thought pieces', Wright and Ricks (1994) sought 'integrative frameworks', while Toyne and Nigh (1998) recommended 'inclusive paradigms', 'process-oriented' research and 'multilevelled' analysis. Later, Buckley and Lessard (2005) called for rigorous 'general' and 'mid-range theories' and for research that is 'theory-driven'. Sullivan and Daniels (2008) recently sought 'greater paradigmatic scope' to recognize both 'humanistic methodological approaches' alongside those able to explore complex systems. Clearly, the field has indulged in introspection and rumination with respect to the methods it uses. In summary, the debate and discussion in previous reviews of the field has centered on three main issues. The most dominant one concerns (1) the balance between focus and 'depth' on the one hand, and the need for interdisciplinary approaches and 'breadth', on the other. Related to this issue is (2), a question of the rigor and appropriateness of the methods employed. Although raised, but not often discussed explicitly, a central aspect of interdisciplinarity has been (3) the relative role of macroeconomic issues (for example, the impact of foreign direct investment (FDI) and the roles of government policy), vis-à-vis microeconomic ones (such as the performance implications of international strategies). Finally, in response to a perceived US-centrism in IB scholarship, intermittently there have been calls for (4) a broader geographical focus.

\section{METHOD}

\section{The Analytical Tool}

The co-occurrence of words used in text provides useful information for a narrative inquiry on a subject (Clandin and Connelly, 2000, Sowa, 2000; Stubbs, 1996); that is “... a word can be defined by its context in usage" (Smith and Humphreys 2006:262, Courtial 1989, Leydesdorff and Hellsten 2006, Lee and Jeong 2008). In this form of inquiry, co-occurring words reflect categories - concepts - that carry meaning 
(Osgood, Suci and Tannenbaum1957, Leydesdorff and Hellsten 2006). Exploiting this potential, we adopt Leximancer, a software text analytic tool, to scientometrically describe and analyze the articles published in JIBS. Suites of journals have been used in other scientometric studies, but these studies have objectives different from our study (e.g., Davarpaah and Aslekia 2008). Leximancer uses empirically validated mathematical algorithms (Metropolis, Rosenbluth, Rosenbluth, Teller and Teller 1953) to make two determinations: (i) the most frequently used concepts within a body of text; and more importantly, (ii) the relationships between these concepts. The approach provides unbiased results (Leximancer 2009) by performing associational analysis of textual data in a language independent manner (Smith 2003). Extending beyond simply coding keywords, Leximancer bootstraps an expanded list of associated terms that signify a concept from the textual data. This boosts the recall of relevant content, and more closely resembles the work conducted by a human coder (who can infer meaning and acknowledge implicit references). A further important component of our analysis is the consideration of 'absence' of a concept, as well as its 'presence'. It is potentially instructive if important concepts fail to occur sufficiently frequently within the text to be identified and associated with other concepts. The Leximancer program has been demonstrated by Smith and Humphreys (2006) to have face validity, stability, reproducibility, correlative validity and functional validity.

The first phase in a Leximancer analysis is a semantic extraction designed to "(1) construct classifiers for multiple concepts that can predict whether a small segment of text contains one or more of the concepts; (2) provide a meaningful name for each concept as a signifier; (3) allow the concept set to characterize the message conveyed by the text corpus; and (4) allow manual customisation of the concept set prior to learning of the representations" (Smith and Humphreys 2006: 263). A second stage of the analysis is to construct a map showing the concepts' relational characteristics, represented as assemblies into clusters. This map permits interpretation of the data that would be too demanding in pure numerical form. It displays several characteristics of the relational association between concepts, as determined through the cooccurrence matrix: (1) concept frequency (reported in tables and demonstrated as brightness of the concept representation dot), (2) total concept connectedness (in a hierarchical order of appearance to enter the map), (3) direct inter-concept relative co-occurrence frequency (numerically and via the intensity of rays emanating from the selected concept to all related others), and (4) total (direct and indirect) inter-concept 
co-occurrence (represented as proximity of one concept to another in the map) (Smith and Humphreys 2006).

\section{The Data}

We assembled all articles from JIBS from the first edition through to the August 2008 edition (volume 39, number 5). This provided the population of 1249 articles, written over approximately 17625 pages. The articles were clustered according to JIBS editorship periods, with the distribution: Ogram 1970 - 1975 and 102 articles, Dymsza 1976 - 1984 and 271 articles, Ricks 1985 - 1992 and 235 articles, Beamish 1993 1997 and 185 articles, Brewer 1998 - 2002 and 214 articles, and Lewin 2003 - 2007 and 242 articles. $^{2}$ For this assembly, we lagged each editorship period by one year as articles accepted by one editor generally run over into publication in the subsequent editor's term. We excluded from the analysis compilations such as book reviews and editorials to retain a focus on articles reflecting the emergence, maintenance and abandonment - the evolution - of significant themes in IB research.

\section{THE 'ALL EDITORS’ MAP - FOUR DECADES IN OVERVIEW}

The IB field was initiated by scholars observing the growing importance of the MNE post-WWII, an absence of its explanation, and application of FDI as a primary mechanism of its international involvement, alongside its international trade activities (e.g., Wright 1970, Beamish and Inkpen 1994, Buckley and Casson 2009). At the time, the MNE as a distinct organizational form was becoming visible throughout the developed world. With business activity in both home and host countries, and by its sheer size, the emerging importance of its power and influence attracted scholars from cognate disciplines. The MNE as a firm operating across country borders formed the domain of this embryonic field. To explain the nature of these enterprises, their investments abroad, and the power and influence they wielded, scholars looked to theory in other disciplines. International trade theory in its various guises, theory from industrial organization, and Coasean theory of the firm alongside transaction cost economics were applied to elucidate

\footnotetext{
${ }^{2}$ According to Garvey (1979:84 in Hull, 1983:315) "like most scientists, most editors have attitudes about what constitutes quality in their journal. These attitudes are influenced by their theoretical bias, their methodological preferences, etc., and they tend to select consulting editors and referees who share them." However, as illustrated in Hull's (1983) analysis of the evolution of Systematic Zoology under its different editorships, editors' influences on the scope and content of a journal are moderated by a host of variables, including, for example, rejection rates and the general development of the discipline, including the 'rhythm of scientific dispute' (p. 339).
} 
these phenomena. At this early stage, MNE activities in home and host markets were center-stage. However, it was not until the late 1970s/early 1980s that the imperfections in these international markets were fully recognized and became fundamental to the theoretical developments in IB.

\section{INSERT FIGURE 1 ABOUT HERE}

Our Leximancer “All editors” analysis and map identifies five distinct concept clusters: 'methods', 'performance', 'strategy', 'manufacturing' and 'exchange rates'. There is a clear separation between the initial four editorial periods and the two more recent Brewer and Lewin periods. This is highlighted by the positioning of the Brewer and Lewin clusters (indicated by the corresponding concept dots in the upper right periphery of the map), diagonally opposite the four earlier editorial periods, with Ogram and Dymsza aligned and Ricks and Beamish loosely aligned, but with the content and scope of all these four editorship periods distant from Brewer and Lewin.

The 'performance' cluster is most proximate to Lewin, and includes the concepts, 'knowledge', 'cultural' and 'entry', with 'resources', 'national' and 'control' sharing a common boundary with the 'strategy' cluster. The 'methods' cluster is most proximate to Brewer, with concepts such as 'variables', 'measurement', 'model', 'value', 'economic' and 'host' sharing a common boundary with the 'strategy' cluster. The 'strategy' cluster contains a dense set of concepts, such as 'system', 'local', 'development', 'subsidiaries', 'organizational', ‘joint', 'process', 'global', 'business', 'managers', 'management', and with 'multinational' on its periphery and common with the 'manufacturing' cluster, and 'host' similarly peripheral and shared with the 'methods' cluster.

The 'strategy' cluster is midway aligned with Lewin, Beamish and possibly Ricks. Dymsza and Ogram are most closely aligned with the 'exchange rates' cluster, comprising the concepts 'risk', 'investment' and 'costs'. 'The 'manufacturing' cluster, most closely aligned with Ogram and Ricks, possibly Dymsza, and lesser so Beamish, includes the concepts 'export', 'industry', 'product', 'companies', 'multinational' and 'Japanese', but extends to overlap with the 'exchange rates' cluster to commonly share 'investment', 'costs' and 'case'. This 'manufacturing' cluster is distant from Lewin and Brewer. Notable absences throughout the entire four decades is an 'internationalization' cluster, a 'theory' cluster, an 'internalization' cluster, a 'services' cluster and a 'culture' cluster. 
The analysis suggests a pattern of development where the IB literature has evolved from a formative stage in which macro-environmental contextual factors were of prime consideration, to its current position in which the firm, its strategy and its performance, have become the dominant interests. To elaborate further from this 'All editors' overview, we now turn to the evolution of the five concept themes that emerged over the six editorships.

\section{INSERT FIGURE 2 ABOUT HERE}

\section{THEMES}

\section{Exchange Rates}

First, we consider the 'exchange rates' theme. Entering JIBS at its inception, in the Ogram editorship, this cluster was little elaborated, associated with the concept 'interest' only:

The benefits of evaluating these financial linkages have increased in the past several years due to a sharp rise in interest rates world-wide as well as to the increased use of exchange rate adjustments by national governments. [T]his paper focuses on the costs associated with borrowing either intracorporate from within or without the corporation when the risk of exchange rate changes is present and different tax rates and regulations are in effect (Shapiro 1984:19).

In the following Dymsza period, other associations entered with 'floating', 'currency', 'risk', 'changes', 'cost', 'capital' and 'changes':

The behavior of currencies under different exchange regimes - floating rates, strictly managed rates, crawling peg rates, and fixed exchange rates - is analyzed in detail. The results support this doctrine, provided the parity exchange rate is derived from an interrelationship of differentials in inflation rates and changes in exchange rates of trading partners, both appropriately weighted by trade shares (Everett, George and Blumberg 1980: 80).

In this period, this cluster became distinct, not overlapping with any other concept clusters (Dymsza 1979). In the Ricks editorship, it fades away, leaving the concepts 'exchange' and 'risk' within a 'methods' cluster, only to re-enter as a separate cluster under Beamish, with no additional concepts included but for 'risk'. 
The purpose of this study is to perform a joint test of the segmentation of world capital markets and the presence of the exchange risk factor in the context of a multifactor asset return model (Choi and Rajan 1997: 31).

The concept 'exchange' remained under Brewer, staying within the 'methods' cluster, but departed under Lewin, leaving the concept 'risk' on the periphery of the 'methods' cluster. This pattern of appearance is consistent with the conjecture that macro-environmental issues were early to enter the IB lexicon, but departed later as firm-specific issues came to dominate. This is not to say that exchange rates consideration is totally absent from our IB literature of late, but it does signal a diminished interest relative to other issues.

INSERT FIGURE 3 ABOUT HERE

\section{Manufacturing}

The 'manufacturing' concept cluster has remained in all editorships until Lewin, reflecting an enduring IB interest in industrial production. It exits in the Lewin editorship, perhaps because services have become more prominent in IB research, although the frequency of the concept 'services' has not reached the Leximancer inclusion threshold. In the initial Ogram editorship, the 'manufacturing' cluster included concepts such as 'industry', 'multinational', 'product', and 'production', highlighting the early IB focus on MNEs in manufacturing industries. This is reinforced by the overlap of this cluster with the 'MNEs' cluster which recognizes concepts such as 'operations', 'subsidiaries', 'domestic' and 'control'.

As early as 1815, the Belgian steel company, Cockerill, put up its first foreign plant in Prussia, thus antedating the first American foreign manufacturing investment by 37 years. During the century and a half that have elapsed since then, the majority of today's large European companies have first sold and then manufactured outside their home countries (Franko 1975: 41).

The 'MNEs' cluster overlaps with an 'FDI' cluster, with the common concepts 'financial', 'domestic' and 'control'. This pattern of interrelationships between the concept clusters 'MNEs', 'FDI' and 'manufacturing' is consistent with the emergence of the IB field and its early interest in the MNE and its involvement in FDI, especially in the form of production subsidiaries overseas, as described by Vernon's PLC theory.

Interest in 'manufacturing' carried over to the Dymsza editorship, but it then associated with the concepts 'exports' and 'technology'. While maintaining the PLC theory orientation, the cluster's scope was 
widened during the Ricks period to include 'costs', 'investment', 'local', 'government' and 'joint ventures' - the latter importantly heralding a new important IB focus.

The product's life-cycle stage is determined by competitive and market forces. Contrary to the prediction of the international product cycle paradigm, this study has found that a product's market performance is neither related to its assembly location nor is it influenced by who assembles the product. If the parent's continuing control over the manufacturing process is not necessary, some form of external assembly (such as minority-participated joint venture or licensing) may lead to a level of product performance not different than if the parent or its subsidiary assembled the product (Kotabe and Omura 1989: 127).

The concept 'government' reflects the increasing importance of host country ('local') governments establishing policy to attract IJV activity (illustrated by the very close proximity of these two concepts in the map). The commonality of these two concepts with the 'strategy' cluster signals the emergence of firms strategizing about IJVs during this period.

Beamish's editorship saw the 'manufacturing' cluster deplete of some of the previous Ricks' concepts, but retaining 'industry', 'investment', costs', 'product' and 'technology', with a new concepts entering this cluster, 'markets'. A lesser overlap with other clusters is noticed, probably signaling a trend towards relatively lesser overarching emphasis on manufacturing as a sector of IB interest. The entry of 'markets' is interesting, possibly suggesting an emerging interest in associating supply side issues - production, costs and investment - with demand side issues. The overlap in clusters that does occur does so with a newly emerged cluster, 'globalization', which for the first time introduces the concept 'theory'. Brewer's editorship sees the 'manufacturing' cluster retained, but with few concepts, 'industry', 'investment', 'products', 'technology' and 'costs', and only marginal overlap with other clusters ('costs' jointly occurs on the fringes of both the 'manufacturing' cluster and a new 'knowledge' cluster). However, and significantly, 'manufacturing' as a cluster exits under Lewin and the concept 'manufacturing' does not appear. This is a significant development.

This minimizes the need for cross-border knowledge transfer considerably, relative to other entry modes. In particular, if the knowledge advantage resides in a manufacturing process, exporting requires no substantial transfer of the process technology, whereas licensing and direct production investment would (Martin and Salomon 2003: 358). 


\section{Methods}

The 'methods' cluster, in the 'All editors' map is represented by the concepts, 'variables', 'measures', 'model', 'value', 'economic', and 'host' shared on the fringe with the 'strategy' cluster. The first three concepts are closely aligned, signaling a strong association, indicating quantitative analysis. They are most proximate to Brewer. A 'methods' cluster is absent from the Ogram editorship at the journal's foundation, with none of the methods concepts identified. The concept 'variables' appears in the Dymsza editorship, but it is isolated from all other concepts. It is only some 15 years after the foundation of JIBS, under the editorship of Ricks, that a 'methods' cluster appears, with the concepts 'model', 'variables', 'studies', 'economic', 'risk', 'domestic', 'exchange' and 'multinational', the latter shared with the 'manufacturing' cluster.

If variables shown to be important in domestic research or hypothesized as important in theoretical models can be extended internationally, then areas of commonality and distinction between domestic and international research may become more clearly delineated (Naumann 1993: 77). While the concepts 'variables', 'model' and 'value' remain in the Beamish editorship, they occur in isolation and are peripheral. Interestingly, the only appearance of the concept 'theory' appears in the Beamish term, closely associated with 'case', and in a new 'globalization' cluster. This could be signaling the emerging importance of case study research for theory- building in this period.

This industry also provides an ideal setting in which to study the role of information and interorganizational networks as sources of competitive advantage. At the firm level and at the individual level, this setting provides an arena in which to build theory and test a range of decision making, risk-taking, and gaming behaviors drawing from a number of perspectives, and to examine the impact of global circadian rhythms on the organization and on the individual (Zaheer 1995: 723). 'Methods' re-appears under Brewer, with the concepts 'variables', 'model', 'measures' and with 'exchange' but this concept is somewhat distant from the other three concepts. There is a remarkable symmetry within the Brewer map, with all concept clusters, including the 'methods' cluster centering on the 'performance' cluster. The concept 'performance' is very strongly represented and is relatively proximate to the 'methods' cluster which could be alluding to an interest in methods for the analysis of performance. 'Methods' 
similarly remains under the Lewin editorship, overlapping with a 'MNEs' cluster, but distant now from 'performance', and including 'risk' on its periphery.

In the downside risk $\mathrm{r}_{\mathrm{i}}$ equation, $\mathrm{x} 0_{\mathrm{i}}$ is a vector of explanatory variables that affect the firm's downside risk, $\mathrm{b}$ is a coefficient vector, and $\mathrm{e}_{\mathrm{i}}$ is the error. The equation is estimated as a Tobit model, since downside risk is truncated at zero (see the variable's measurement below), and the fitted value for $\mathrm{n}_{\mathrm{i}}$ is used to control for simultaneity, and $\mathrm{d}$ is incorporated as an additional regressor to correct for the selectivity bias (Tong and Reuer 2007: 220).

Alongside the change in contextual orientation, we observe some developments in methodology. The ways in which scholars within a field or a discipline approach their studies, and the methods they use to establish their empirical bases, are important. These determine the acceptability of their studies and the implications drawn from them, vitally affecting the balance of exchange in ideas between IB and its cognate disciplines and fields. Our maps show that since the mid 1970s, the methods used in the field have been important throughout the four decades analyzed. Across the entire period, there is an enduring strong quantitative sense revealed, with concepts such as 'variables', 'measures' and 'model' increasingly prominent. The concept 'theory' appears but once in the maps presented here, in the Beamish editorship, interestingly alongside 'case'.

\section{Performance}

In the early Ogram and Dymsza editorships, 'performance' is not identified. It enters during the Ricks period as a concept within a 'strategy' cluster, but not proximate to 'strategy' as a concept. It is more associated with the concepts 'management' and 'managers', and is shared with a new 'organization' cluster in this period.

In Korea, job evaluations are nonsystematic, promotions are predicated on seniority, salary levels are based on educational level and seniority, and incentive compensation tends to be nonexistent ... In many cases, little prospect for long-term reward or promotion is available to ordinary whitecollar employees, regardless of their performance (Dubinsky, Michaels, Kotabe, Lim and Moon 1992: 94). 
Under the Beamish editorship, the concept 'performance' appears centered in a new 'culture' cluster, moving even further from its association with 'strategy' and appearing quite peripheral within the map generally. However, under Brewer, 'performance’ assumes center-stage with heightened significance, connecting all other clusters, 'manufacturing', 'methods', 'culture', 'MNEs' and 'knowledge'.

Indeed, cultural incompatibility may cost more than strategic incompatibility in organizational alliances. Different culture types create different psychological environments for the joint venture or the merged company, and differences in practices have a negative influence on performance (Pothukuchi, Damanpour, Choi, Chen and Park 2002: 245).

While remaining as a concept during the Lewin term, strongly associated with the concept 'strategy', it loses its centrality under Lewin, associating instead with 'resources', 'global' and 'multinational'.

This is to be contrasted with the evolution and pathway of resource deployment associated with traditional MNEs, or even with born globals that follow traditional but accelerated internationalisation processes ... Much more can and needs to be done to map out the relative occurrence of different entry points and pathways into the global marketplace, and to understand their sustainability and performance implications (Matthews and Zander 2007: 388).

\section{Strategy}

The 'strategy' cluster is prominent in the 'All editors' map where it encapsulates many concepts. This cluster identifies the transition from the first four-editorship terms to the subsequent Brewer-Lewin terms. 'Strategy' as a concept does not appear in the early Ogram and Dymsza terms (but in Ogram's editorship, a 'policy' cluster signifies interest at this time in 'government' and 'economic' policy).

The structural deficiencies of capital markets, ideological convictions regarding the role of government in capital markets and historically ingrained tendencies to maintain sovereignty in monetary, fiscal and other economic matters render any liberalization extremely unlikely. It is true from time to time restrictions in individual capital markets will be loosened, especially if a capital outflow is desired for reasons of internal economic policy (Dufey 1970: 70).

A strong 'strategy' cluster is introduced under Ricks, which includes many concepts, and for the first time, a country name appears - 'Japanese'. This 'strategy' cluster also includes 'management', 'performance', 'process', 'subsidiaries, 'joint ventures', 'local', 'global' and 'marketing'. 
In the functional structure, still favored by so many British companies, such focus and responsibility is lost. The group decision-making process and continuous, informal feedback that characterize the Japanese subsidiaries also reinforce the commitment and clarity of strategy more effectively than the hierarchical, top-down approach of their competitors (Doyle Saunders and Wong 1986: 44). In the Beamish term, a 'strategy' cluster remained significant but with the concept, 'organizational' entering, whereas earlier, under Ricks, the 'organizational' concept formed its own 'organization' cluster. Several concepts within the 'strategy' cluster overlap with the ' $M N E$ ' cluster, including 'subsidiaries', 'legal', 'process' and 'knowledge' - the first time the 'knowledge' concept has entered the maps. With Brewer, 'strategy' loses its cluster status, appearing as the concept 'strategic' on the fringe of a new 'knowledge' cluster, also bordering on a 'MNEs' cluster, very proximate to 'resources'. However, 'strategy' regains its cluster status under Lewin, now associated with 'performance', 'resources', 'global' and 'multinational'. 'Knowledge' and 'strategy' become separate clusters under Lewin, while 'performance' loses its cluster status and centrality. 'Resources', 'local' and 'ventures' bridge these two clusters.

\section{Geographic Scope}

In IB, geography matters. Since its inception, the field has derived legitimacy through the observed geographical diffusion of MNE activities. In contrast, the geographic scope of IB research has long reflected the national origin of IB scholars, who are primarily North American. Based on an examination of 602 JIBS articles, Thomas and colleagues (1994: 685) concluded that “... 'American influenced' research became institutionalized and stored in the collective 'mental map' of international business scholars... [Moreover,] non-US scholars or non-US-trained scholars, unable to read the necessary signals, are less likely to be aware of the rules of the game, partially accounting for their absence in published research... perpetuating the cycle of parochialism.” In the same year, however, Wright and Ricks (1994), without citing empirical evidence, reported an increasing diversity in the geographic scope of IB research.

A simple frequency count of geographical names occurring in the JIBS articles investigated here (Figure 8) tends to support Wright and Ricks (1994). North American dominance is revealed only for the early Ogram period (1970-75). It thereafter declined, to then remain stable throughout the Dymsza, Ricks and Beamish periods (1976-1997). In the final two editorships (Brewer and Lewin, 1998-2007), the share of geographical name references represented by the US and Canada dropped to around 10 per cent. This 
decline reflected a growing interest in Asia, which in the mid-2000s accounted for nearly 60 per cent of geographical name references. Interest in Asia first centered on Japan (from Dymsza through to Beamish, 1976-1997), followed by a strong rise in the number of references to China. Interest in Europe has been significant and has been sustained over the four decades, in the final period accounting for nearly 30 per cent of the references to geographical names. In contrast, Latin America, which enjoyed considerable attention in the early Ogram period, has since the mid-1970s not attracted substantive research interest, with only slightly more than two per cent in the final period. Clearly, the Figure 8 illustrates a greater geographical diversity in the focus of IB research, increasing over time. However, it also suggests the existence of untapped research opportunities, primarily in Latin America and in other economically important countries, such as India and Russia.

\section{DISCUSSION}

The field of international business emerged as a collective effort on the part of scholars from various disciplines who shared an interest in the MNE, how to manage its complexity and in achieving a better understanding of its effects in both home and host countries. These questions demanded explanations not existing at the time and provided a raison d'être for this new field, inviting contributions from disciplines as diverse as economics, finance, sociology, geography, business history, anthropology, political science and others. First sought were descriptive studies that brought an understanding of the scope of the activities and importance of these enterprises. Geography was important as MNEs were characterized by their geographical dispersion, and country differences were instrumental in describing and explaining the activities undertaken at home and overseas - macro-environmental issues entered these early descriptions.

Multidisciplinarity characterized this early formative period as the community of scholars began to form, bringing with them their disciplinary heritages. The field actively participated in the exchange of ideas, initially leveraging its members' disciplinary diversity. William Ogram, the first editor of JIBS in his inaugural editorial identified “ ... issues relating to management, public policy, research and education in International Business" as the journal's scope, with the determining criterion for publication acceptance to be "instructiveness, irrespective of whether it was normative or descriptive" (Ogram 1981:8). Subsequently, William Dymsza, the second editor of JIBS, stated that JIBS would publish “...significant basic or applied research and conceptual or theoretical contributions to international or comparative business" and that as a 
result of the diverse backgrounds of those attracted to the field, and the "... very nature of the international business discipline, the articles published will vary considerably in the orientation, methodology, utilized level of sophistication, and nature of their contribution. The... underlying methodology should be a matter of indifference and... should be dictated by the nature of the task assumed by the author" (Dymsza and Vambery 1979:7).

Importantly, at the inception of JIBS, Wright (1970), on the basis of IB scholars' expert opinions, had called for a broad and interdisciplinary orientation, bridging the macro-environmental considerations with analysis of firm-level activity. This has been shown to be prophetic. This call for interdisciplinarity has periodically been raised by scholars who believed that this was essential to better cope with the complexity of IB issues (see, e.g. Terpstra, 1973; Dymsza, 1984; Dunning,1989; Wright and Ricks, 1994; and Shenkar, 2004). Presumably the call persisted because there was a belief that this had not happened, although more recently, the Editor-in-Chief, Eden (2008) proclaimed interdisciplinarity to be a core characteristic of the field.

In our analysis, we do find evidence of interdisciplinarity, particularly of late. While the ' $M N E$ ' has remained a cluster of interest throughout all editorships studied here, albeit with a diversion into 'organization' in the Ricks term, its association with other concepts has altered over time, from an initial association with 'FDI' and 'manufacturing', through an association with 'strategy' to then include 'culture' with 'strategy' and bordering on 'globalization', to subsequently include 'knowledge' with 'culture' and relating strongly with 'performance', and of late to bring 'governance' into its scope. This pattern of increasing association with a widening array of other concepts reflects preparedness to open the borders of the IB domain to contributions from other fields and disciplines (c.f. Peng 2001).

The findings of a recent study of the structure of JIBS' 'social networks' (Chabowski, Hult, Kiyak and Mena 2009) parallel these findings. In their early period, 1976-1986, the MNE is associated with 'competitiveness', 'theory', and 'foreign investment'; in their latter period, 1998-2008, it is associated with concepts such as 'knowledge development', 'transaction costs', 'international production', and 'resource advantage'3. While Hofer et al. (2010: 860) report the five most frequently occurring keywords in their 3-

\footnotetext{
${ }^{3}$ Curiously, Chabowski and colleagues (2009) in a recent analysis of the evolution of JIBS' social network did not identify an independent research cluster around 'strategy' in the latter periods of their analysis. We suspect that this is a consequence of their methodology, which was governed by the patterns of bibliometric mapping proceeding from a set of 'most often cited papers'; the method employed here imposes no such restrictions.
} 
year 2006-2008 study of recent Academy of International Business conference papers are the MNE, emerging markets, FDI, internationalization and knowledge management, and that there is a core centered on the MNE with a "semi-periphery and periphery of reasoning" where the "boundaries of international business are permeable".

The enduring importance of the MNE is illuminating, as it signals the key to IB's 'comparative advantage', possibly 'absolute advantage' (Peng 2004). Has the IB field exhausted all aspects of the MNE and understands it fully, and if so, can IB lay claim to a theory of the MNE from which other fields and disciplines benefit? Is internalization theory widely accepted beyond the field, and even more so, is internalization theory accepted within the field as 'the' explanation of the very nature of the MNE? While the MNE provided the raison d'être for the emergence of the field, it has always been understood to operate within a macro-environmental context. Hence, one might expect that as the field matures, bridging the gap between 'macro' and 'micro' should be confronted, particularly as the JIBS definition of IB included: "First, it is concerned with firm-level business activity that crosses national boundaries ... [and] it is concerned in some way with the interrelationships between the operations of the business firm and the international or foreign environments in which the firm operates" (Wright and Ricks 1994: 689). Wright (1970) clearly recognized these multi-level interactions and scoping for the field, as did Toyne and Nigh (1998) and Shenkar (2004).

The distinct divide between a focus on the field's macro-environmental issues in the four editorships prior to Brewer, particularly around 'exchange rates', and in the Brewer term, around 'performance', 'culture' and 'knowledge', joined by 'governance' in the Lewin term, signals a significant transition. This is possibly most succinctly captured in Peng's (2004) 'What determines the international success and failure of firms?' response to Buckley's (2002) 'what is the big question?' Clearly, Peng's question offers a broad scope ; it entices novelty as internal and environmental factors impinge on the firm's exercise of agency change over time. Peng's question addresses both the firm and its interrelationships with the macroenvironment. A field that lays claim to relevance in this wide domain must be prepared and able to continually address new issues as these emerge. This, of course, is a formidable challenge, and probably impossible to fully embrace. For example, organized international terrorism has altered the way in which international firms approach their international business operations, but has the field, through JIBS, embraced research in this area? Similarly, is the field effectively addressing the likely social, political and 
economic effects of global climate change on the activities, success and possible failure of international firms? Has the IB field fully embraced the definition of its scope as it was originally intended? Or is there, as Dymsza suggested, three decades ago, a contradiction between the discipline's scientific goals and its contemporaneity and relevance?

We have had manuscripts on some of these issues [international oil and energy problems; bribery and corruption, trade with the People's Republic of China, and international codes of conduct for multinational enterprise] but they have not passed the review process because they did not make significant contributions. Although scholarly journals such as JIBS cannot serve primarily as a forum for current issues, we strongly encourage the submission of such articles when they involve significant basic or applied research with sound methodology or when they make important conceptual contributions. JIBS must maintain its scholarly standards... (Dymsza 1979: 6).

Interestingly, while the MNE had been central to these first two editorship periods - as revealed in our illustrative maps - it is not represented on the map for the third editorship period. However, David Ricks, editor at the time, reported that “... the core of international business research deals with the multinational enterprise (MNE), the exporting or importing firm, and the problems which are encountered by these firms... and also functionally oriented topics such as international financial management, international marketing management, international accounting management, international strategy, international management, etc" (Ricks 1991: front-page). The MNE re-enters to be central in the Paul Beamish editorship period, remains in the Tom Brewer period and is central again in the final editorship period studied here, that of Arie Lewin. It is during the later periods, 1992-2007, that strategy and performance become prominent.

The Beamish editorship marks a transition between the earlier emphasis on macro-environmental issues to the more recent focus on micro firm-level issues, coupled with increased concept diversity: "Editorially, focus will continue on aspects of the multinational enterprise, and comparative (cross cultural) research. Interdisciplinary and cross-functional international business research is welcome. JIBS looks for papers which are exceptional in one or more of the areas of theory, evidence, methodology or innovation." (Beamish 1993: front-page). The centrality of the MNE was clearly evidenced in the subsequent editorship period, with the Brewer stewardship "bracketed” by “... a special symposium on "The Multinational 
Enterprise and Economic Analysis,"' and a symposium on "The Future of the Multinational"... Since the multinational firm (or global corporation) remains a core topical concern of international business studies, it is entirely appropriate that these two closely-related symposia bracket my term as Editor of JIBS" (Brewer 2002: xi).

While we do not have the data at hand to make strong conjecture on how the IB field rates in the balance of exchange for research methods, there has been a trend to greater 'sophistication' in the methods used in published articles. However, if it is true that the competitive advantage of the IB field vis-à-vis other functionally-specific disciplines ensues from its claim to the MNE and its interrelationships with the macroenvironmental context, it might have been expected that its scholars would have developed new and better multi-level analytics, for example, to grapple with research issues at the interface between the macro environmental / micro firm-specific domains. Likewise, it could perhaps have progressed further in the development of processual analytics to better understand the evolutionary dynamics of the MNE as an organizational form, adapting innovatively to changing contexts. It remains for further study to inquire more specifically into what extent IB as a field has provided novel methods, and improvement of existing ones.

Over time, the international business field has leveraged its cognate disciplines/fields to import ideas and methods, successfully applying them to its core subject of study, the MNE. We confirm the interdisciplinarity that Lorraine Eden, the Editor-in Chief of JIBS, expounded of the field in her inaugural editorial (Eden 2008). However, an important limitation of our analysis is that we are unable to inform the question of whether the field has been extended to "new and important theoretical papers that extend the intellectual reach of international business", as called for by Arie Lewin (Lewin 2003:1). This remains an enticing topic for future research.

\section{CONCLUDING REMARKS}

We present a scientometric analysis of $J I B S^{\prime}$ articles across six editorships over four decades to explore the evolution of the IB field. Exploitation of the Leximancer software for such a scientometric analysis is novel in the scientometry field and has enabled us to uncover new and valuable findings regarding the evolution of the international business field. Over time, IB has leveraged its cognate disciplines to import ideas and methods, successfully applying them to its core subject of study, the MNE. We show an 
evolutionary progression from a formative and extended emphasis on macro-environmental issues that impact on the MNE to a more recent focus on micro-economic, firm-level ones. However, throughout the period, the MNE maintains its pre-eminence as the key vehicle for international business activity and a key focus of international business research. While the field is rich in concepts, which have changed over time in response to changing macro- and micro-environmental conditions, this focus on the MNE has been enduring and confirms a sustainable competitive advantage for the field of international business. The MNE has been and remains a 'moving target', and searches for the 'next big question' should remain in this domain. 


\section{REFERENCES}

Arpan, J.S., Flowers, E.B. \& Ricks, D.A. (1981). Foreign direct investment in the United States: The state of knowledge in research. Journal of International Business Studies, 2(1): 137-154.

Beamish, P.W. (1993). Letter from the Editor-in-Chief. Journal of International Business Studies, 24(1): front-pages.

Boddewyn, J.J. (1981). Comparative marketing: the first twenty-five years. Journal of International Business Studies, 12(1): 61-79.

Brewer, T.L. (2002). Letter from the Editor-in-Chief. Journal of International Business Studies, 38(4): xixii.

Buckley, P.J. (2002). Is the International Business research agenda running out of steam? Journal of International Business Studies, 33(2): 365-373.

Buckley, P.J. \& Casson, M.C. (2009). The internalisation theory of the multinational enterprise: A review of the progress of a research agenda after 30 years. Journal of International Business Studies, 40(9): $1563-1580$.

Buckley, P. J. \& Lessard, D.R. (2005). Regaining the edge for international business research. Journal of International Business Studies, 36(6): 595-599.

Caves, R. E. (1998). Research on international business: problems and prospects. Journal of International Business Studies, 29(1): 5-19.

Chabowski, B.R., Hult, G.T.M., Kiyak, T. \& Mena, J.A. (2009 in-press). The structure of JIBS's social network and the relevance of intra-country variation: A typology for future research. Journal of International Business Studies, 1-10.

Chandy, P.R. \& Williams, T.G.E. (1994)._The impact of journals and authors on international business. Journal of International Business Studies, 25(4): 715-28.

Choi, J.J. \& Rajan, M. (1997). A joint test of market segmentation and exchange risk factor in international capital markets. Journal of International Business Studies, 28(1): 29-49.

Clandinin, D.J. \& F. Michael Connelly, F.M. (2000). Narrative inquiry: Experience and story in qualitative research. San Francisco: Jossey-Bass Publishers.

Courtial, J.P. (1989). Qualitative models, quantitative tools and network analysis. Scientometrics, 15 (5/6): 527-534. 
Daniels, J.D. (1991). Relevance in international business research: A need for more linkages. Journal of International Business Studies, 22(2): 177-186.

Davarpanah, M.R. \& Aslekia, S. (2008). A scientmetric analysis of international LIS journals: Productivity and characteristics. Scientometrics, 77 (1): 21-39.

Doyle, P., Saunders, J. \& Wong, V. (1986). Japanese marketing strategies in the UK: A comparative study. Journal of International Business Studies, 17(1): 27-46.

Dubinsky, A.J., Michaels, R.E., Kotabe, M., Lim, C.U. \& Moon, H.E. (1992). Influence of role stress on industrial salespeople's work outcomes in the United States, Japan and Korea. Journal of International Business Studies, 23(1): 77-99.

Dufey, G. (1970).The Eurobond market: Its significance for international financial managements. Journal of International Business Studies, 1(1): 65-81.

Dunfee, T.W. \& Ricks, D.A. (1971). Joint-efforts programs: A proposal for integration of international and functional concepts. Journal of International Business Studies, 2(1): 61-67.

Dunning, J.H. (1989). The study of international business: A plea for a more interdisciplinary approach. Journal of International Business Studies, 20(3): 411-436.

Dymsza, W.A. (1979). Letter from the Editor. Journal of International Business Studies, 10(1): 6-7.

Dymsza, W.A. (1984). Future international business research and multidisciplinary studies. Journal of International Business Studies, 15(1): 9-13.

Dymsza, W.A. \& Vambery, R. C. (1979). Letter from the Editors. Journal of International Business Studies, 10(2): 6-7.

Eden, L. (2008). Letter from the Editor-in-Chief. Journal of International Business Studies, 39: 1- 7.

Ervin, M., \& Toyne, B. (198). The AIB membership: Who are we, and what are we interested in. Journal of International Business Studies, 18(2): 89-100.

Everett, R.M., George, A.M. \& Blumberg, A. (1980). Appraising currency strengths and weaknesses: An operational model for calculating parity exchange rates. Journal of International Business Studies, 11(2): 80-91.

Franko, L.G. (1975). Patterns in the multinational spread of Continental European enterprise. Journal of International Business Studies, 6(2): 41-53.

Garfield, E. (1998). The Impact Factor and using it correctly. Der Unfallchirurg, 101(6): 413-414. 
Griffith, D.A., Cavusgil, S.T. \& Xu, S. (2008). Emerging themes in international business research. Journal of International Business Studies, 39(7): 1220-1235.

Hawkins, R.G. (1984). International Business in academia: The state of the field. Journal of International Business Studies, 15(3): 13-18.

Hofer, K.M., Smejkal, A.E., Bilgin, F.Z. \& Wuehrer, G.A. (2010). Conference proceedings as a matter of bibliometric sudies: The Academy of International Business 2006-2008. Scientometrics, 84: 845862 (online DOI 10.1007/S11192-010-0216-6).

Hull, D.L. (1983). Thirty-one years of systematic Zoology. Systematic Zoology, 32(4): 315-342. Inkpen, A.C. \& Beamish, P.W. (1994). An analysis of twenty-five years of research in Journal of International Business Studies. Journal of International Business Studies, 25(4): 703-713.

Journal of International Business Studies. (2011). http://www.palgrave-journals.com/jibs/index.html. accessed January 17, 2011.

Kotabe, M. \& Omura, G.S. (1989). Sourcing strategies of European and Japanese multinationals: A comparison. Journal of International Business Studies, 20(1): 113-130.

Lee, B. \& Jeong, Y-I. (2008). Mapping Korea’s national R\&D domain of robot technology by using coword analysis. Scientometrics, 77 (1): 3-19.

Lessard, D.R., Wells Jr., L.T. \& Brandt, W.K. (1983). Suggestions for research themes and publications. Journal of International Business Studies, 14(2): 9-13.

Leximancer (2009). Leximancer: the why, not just the what. Leximancer Manual, Version 3.07. Brisbane: Leximancer Pty. Ltd., The University of Queensland.

Leydesdorff, L. \& Hellsten, L. (2006). Measuring the meaning of words in contexts: An automated analysis of controversies about 'Monarch butterflies,' 'Frankenfoods,' and 'stem cells'. Scientometrics, 67 (2): 231-258.

Martin, X. \& Salomon, R. (2003). Knowledge transfer capacity and its implications for the theory of the multinational corporation. Journal of International Business Studies, 34(4): 356-373.

Mathews, J.A., \& Zander, I. (2007). The international entrepreneurial dynamics of accelerated internationalization. Journal of International Business Studies, 38(3): 387-403.

Metropolis, N., Rosenbluth, A.W., Rosenbluth, M.N., Teller, A.H. \& Teller, E. (1953). Equation of state calculations by fast computing machines. Journal of Chemical Physics, 21(6): 1087-1092. 
Naumann, E. (1993). Organizational predictors of expatriate job satisfaction. Journal of International Business Studies, 24(1): 61-80.

Ogram, E.W. (1981). The early days of JIBS at Georgia State University, 1970 - 1975. Journal of International Business Studies, 12(1): 7-9.

Osgood, C.E., Suci, G.J. \& Tannenbaum, P.H. (1957). The measurement of meaning. Urbana: University of Illinois Press.

Peng, M.W. (2004). Identifying the big question in international business research. Journal of International Business Studies, 35(2): 99-108.

Pothukuchi, V., Damanpour, F., Choi, J., Chen, C.C. \& Park, S.H. (2002). National and organizational culture differences and international joint venture performance. Journal of International Business Studies, 33(2): 243-265.

Ricks, D.A. (1985). International business research: Past, present and future. Journal of International Business Studies, 16(2): 1-4.

Ricks, D.A. (1991). Letter from the Editor-in-Chief, Journal of International Business Studies, 22(1): front-pages.

Rooney, D. (2005). Knowledge, economy, technology and society: The politics of discourse. Telematics and Informatics, 22(4): 405-422.

Roth, K., Schweiger, D.M. \& Morrison, A.J. (1991). Global strategy implementation at the business unit level: Operational capabilities and administrative mechanisms. Journal of International Business Studies, 22(3): 369-402.

Sekaran, U. (1983). Methodological, theoretical issues and advancements in cross-cultural research. Journal of International Business Studies, 14(2): 61-73.

Shapiro, A.C. (1984). The impact of taxation on the currency-of-denomination decision for long-term foreign borrowing and lending. Journal of International Business Studies, 15(1): 15-25.

Shenkar, O. (2004). One more time: International business in a global economy. Journal of International Business Studies, 35(2): 161-71.

Smith, A.E. (2003). Automatic extraction of semantic networks from text using Leximancer. Paper presented at the Human Language Technology Conference, Edmonton. 
Smith, A.E., \& Humphreys, M.S. (2006). Evaluation of unsupervised semantic mapping of natural language with Leximancer concept mapping. Behavior Research Methods, 38(2): 262.

Sowa, J.F. (2000). Knowledge representation: Logical, philosophical, and computational functions. Pacific Grove, CA: Brooks Cole,

Stubbs, M. (1996). Text and corpus analysis: Computer-assisted studies of language and culture. Oxford: Blackwell.

Sullivan, D. (1998). Cognitive tendencies in international business research: Implications of a 'narrow vision'. Journal of International Business Studies, 29(4): 837-862.

Sullivan, D.P. \& Daniels, J.D. (2008). Innovation in international business research: A call for multiple paradigms. Journal of International Business Studies, 39(6): 1081-1090.

Terpstra, V. (1973). The future of the international business professor. Journal of International Business Studies, 4(1): 67-78.

Thomas, A.S., Shenkar, O. \& Clarke, L. (1994). The globalisation of our mental maps: Evaluating the geographic scope of JIBS coverage. Journal of International Business Studies, 25(4): 675-686.

Tong, T.W. \& Reuer, J. J. (2007). Real options in multinational corporations: Organizational challenges and risk implications. Journal of International Business Studies, 38(2): 215-230.

Toyne, B. \& Nigh, D. (1998). A more expansive view of international business. Journal of International Business Studies, 29 (4): 863-875.

Weber, R.P. (1990). Basic Content Analysis. Newbury Park, Calif.: Sage Publications.

Wright, R.W. \& Ricks, D.A. (1994). Trends in international business research: Twenty-five years later. Journal of International Business Studies, 25(4): 687-701.

Wright, R.W. (1970). Trends in International Business research. Journal of International Business Studies, 1(1): 109-123.

Zaheer, S. (1995). Circadian rhythms: The effects of global market integration in the currency trading industry. Journal of International Business Studies, 26(4): 699-728. 


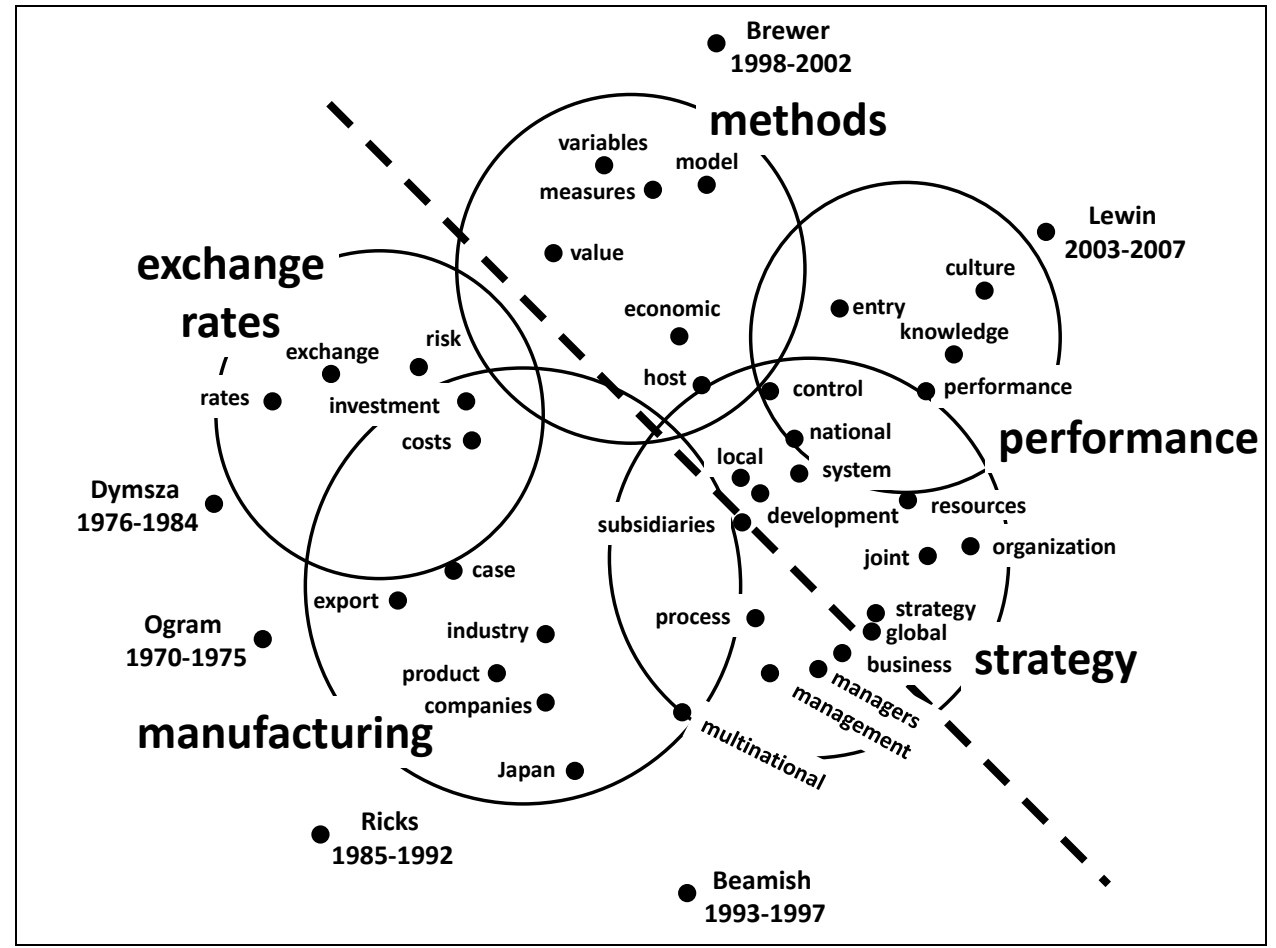

Figure 1 All editors map.

\section{0-1975}

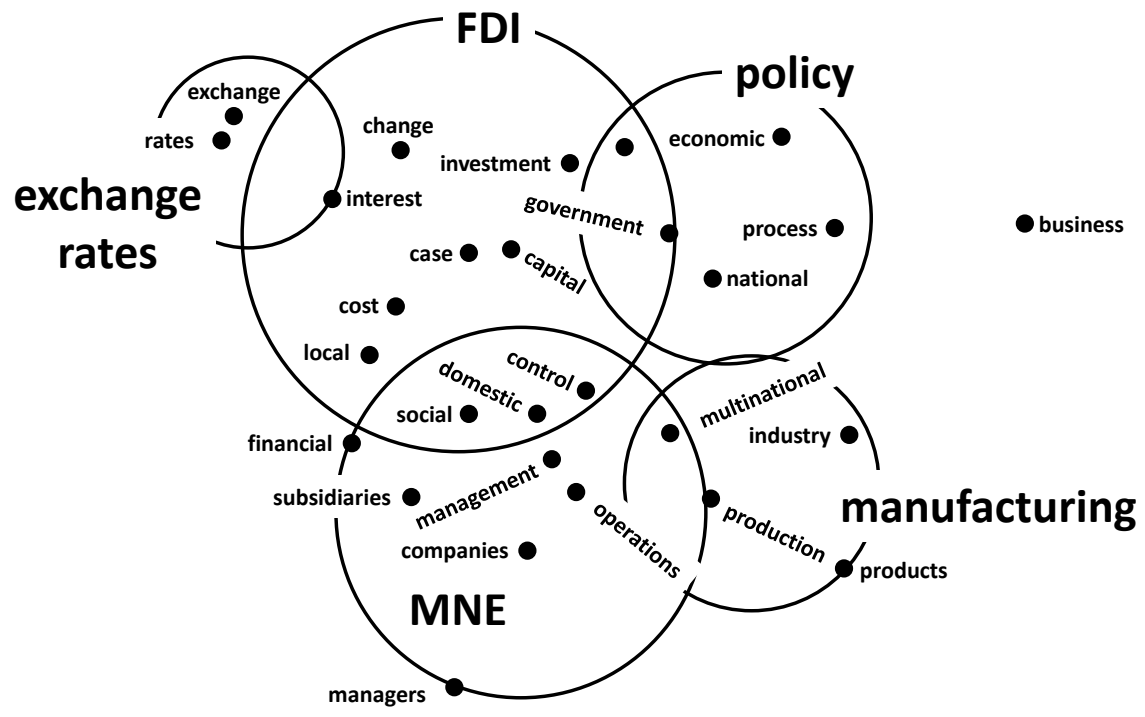

Figure 2 Ogram editorship map. 


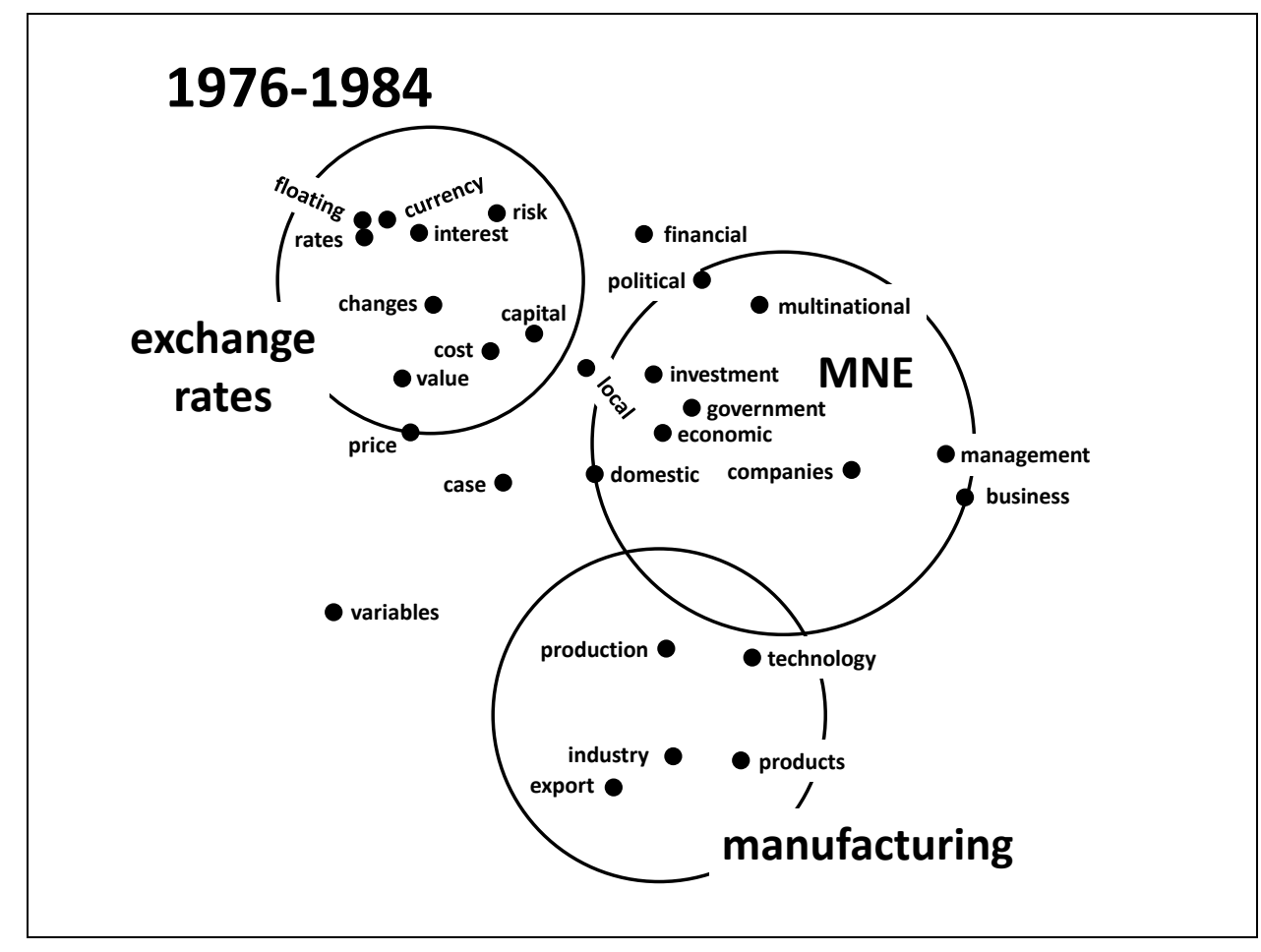

Figure 3 Dymsza editorship map.

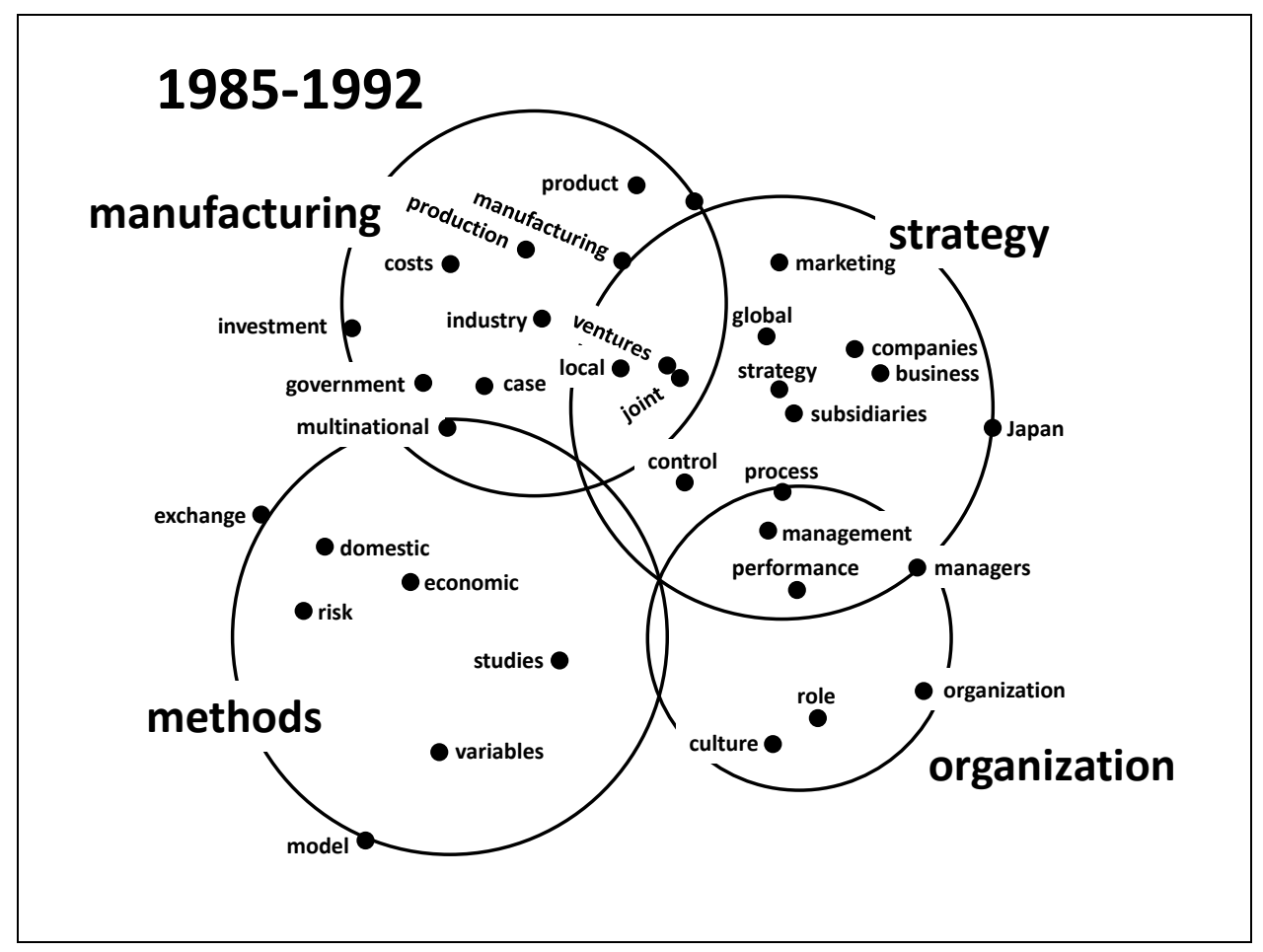

Figure 4 Ricks editorship map. 


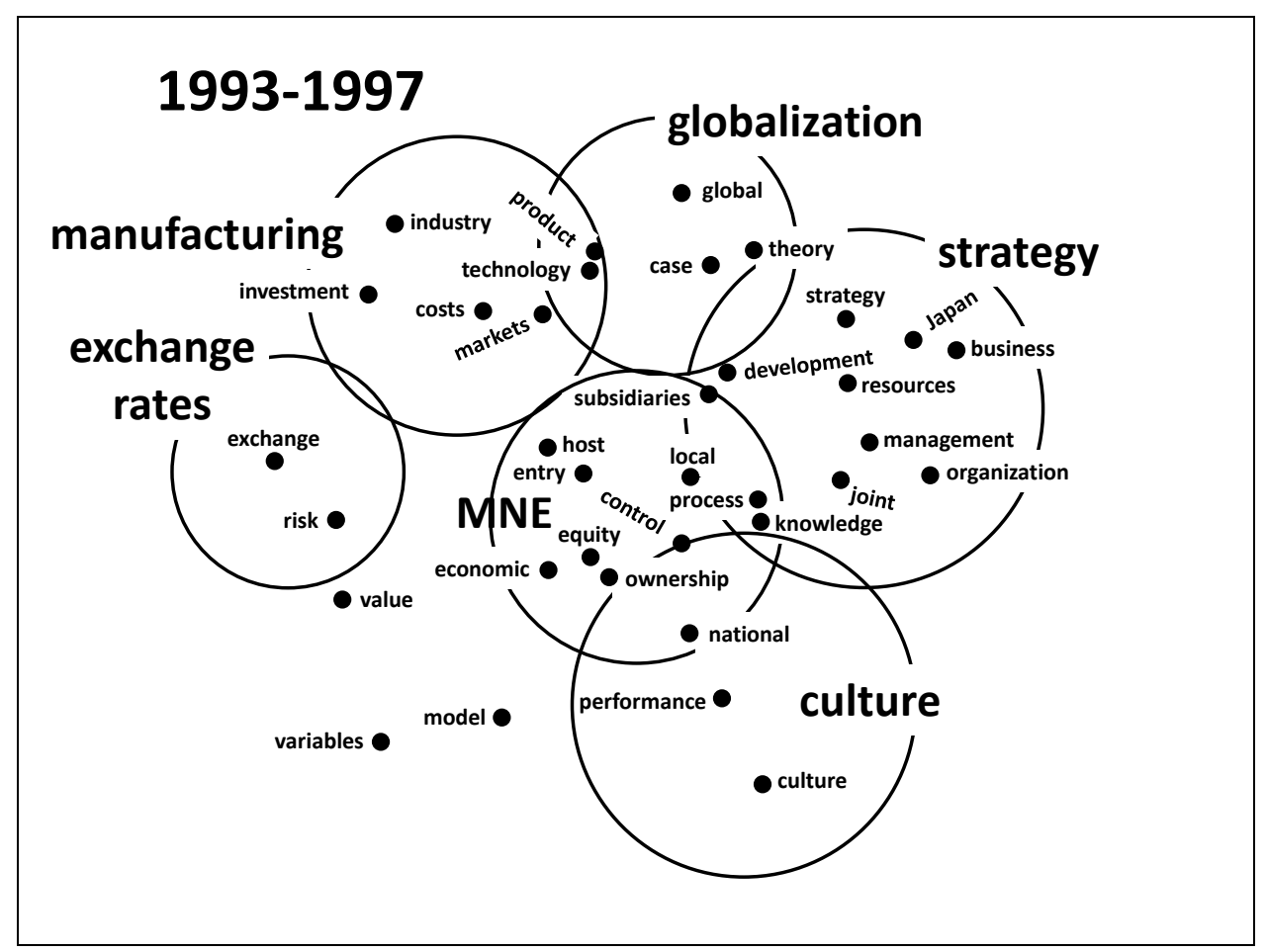

Figure 5 Beamish editorship map.

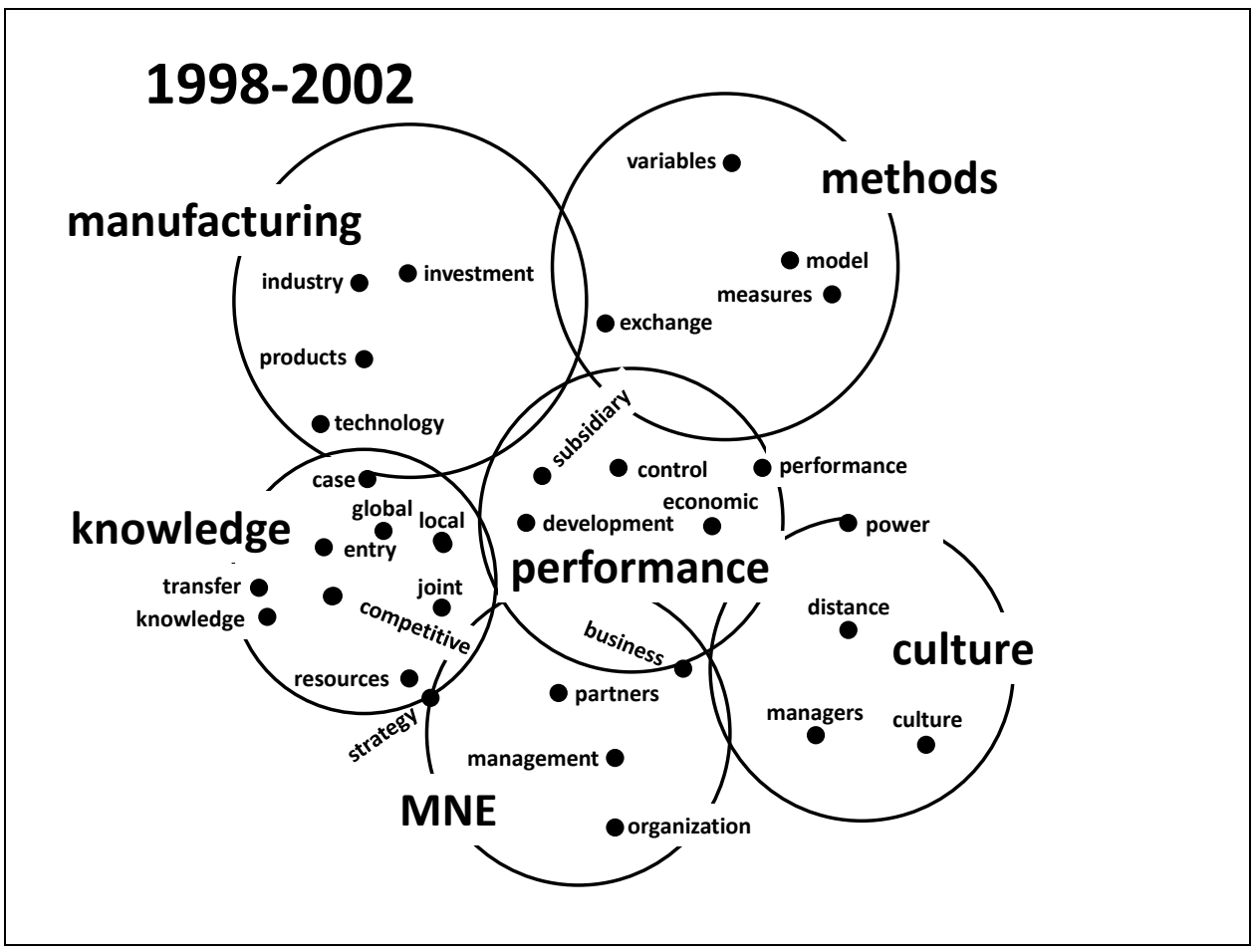

Figure 6 Brewer editorship map. 


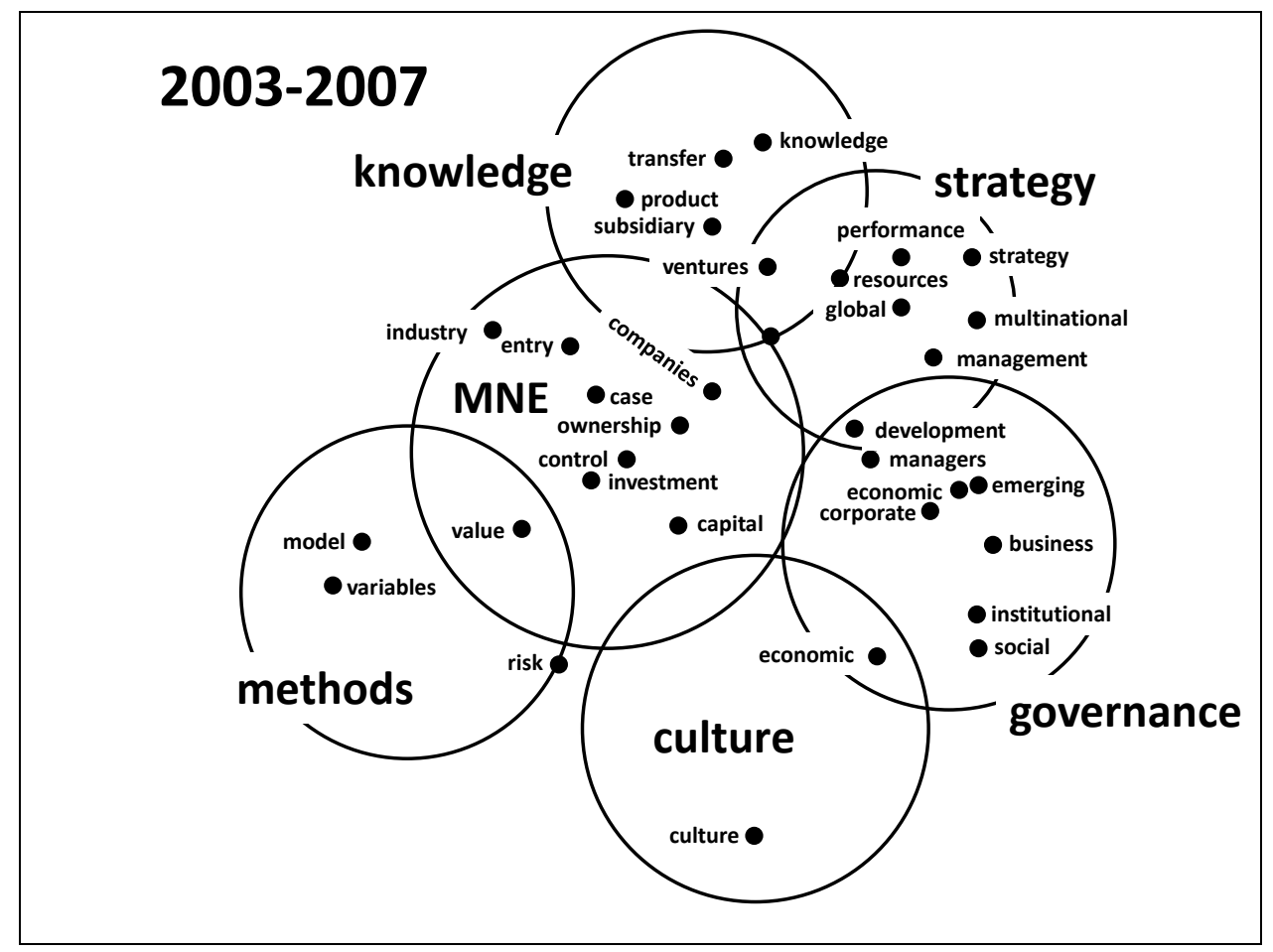

Figure 7 Lewin editorship map.

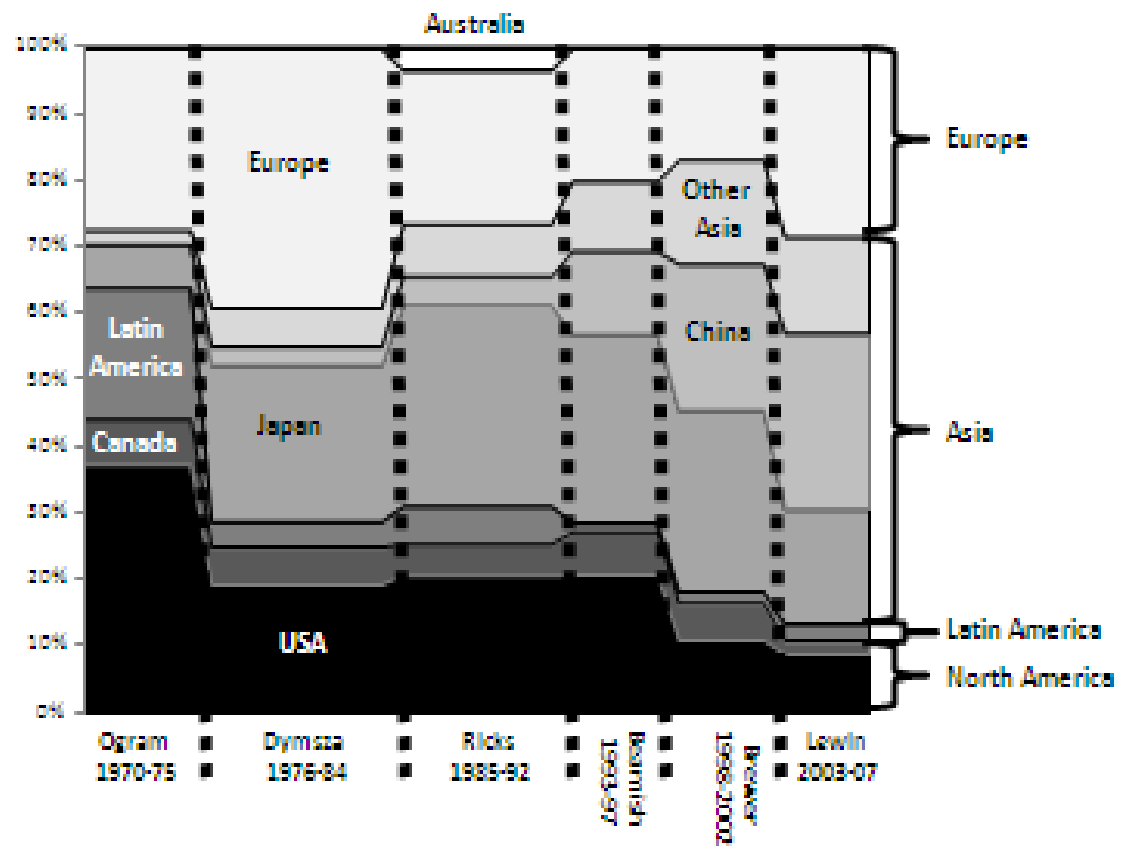

Figure 8 Relative frequency of geographical name references in JIBS articles 1970-2008. 
Table 1

\begin{tabular}{|c|c|c|c|c|}
\hline & Author (date) & Nature of article & Evolution of IB Research & Recommendations \\
\hline \multirow{3}{*}{ 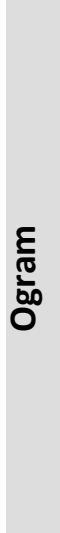 } & Wright (1970) & $\begin{array}{l}\text { Empirical ( } 411 \text { IB } \\
\text { projects; expert } \\
\text { opinions) }\end{array}$ & $\begin{array}{l}\text { Increasing diversity and broader issues (e.g. strategy) that transcend } \\
\text { early emphasis on functional boundaries; growing methodological } \\
\text { sophistication; Greater European scholarship }\end{array}$ & $\begin{array}{l}\text { Continuing breadth and interdisciplinary nature in future direc- } \\
\text { tions, with clear linkages between environment and firm-level } \\
\text { business activity }\end{array}$ \\
\hline & $\begin{array}{l}\text { Dunfee and } \\
\text { Ricks (1971) }\end{array}$ & Thought piece & $\begin{array}{l}\text { Development of interdisciplinary field challenged by resourcing and } \\
\text { cross-faculty communication }\end{array}$ & 'Joint effort' approach of multidisciplinary teams \\
\hline & $\begin{array}{l}\text { Terpstra } \\
(1973)\end{array}$ & $\begin{array}{l}\text { Presidential } \\
\text { address }\end{array}$ & Not described & $\begin{array}{l}\text { Continuing need for research on current practices of firms, but } \\
\text { with greater future orientation and focus on unique IB problems; } \\
\text { multi-country and comparative research, not US centric; inter- } \\
\text { disciplinary collaborations with non-business fields }\end{array}$ \\
\hline \multirow{3}{*}{ ถู } & $\begin{array}{l}\text { Boddewyn } \\
\text { (1981) }\end{array}$ & Thought piece & $\begin{array}{l}\text { Little progress made over } 15 \text { years in the integration of cross-cultural } \\
\text { comparative findings in marketing and consumer behavior texts }\end{array}$ & No overarching conclusions. \\
\hline & $\begin{array}{l}\text { Arpan, } \\
\text { Flowers and } \\
\text { Ricks (1981) }\end{array}$ & $\begin{array}{l}\text { Empirical (100+ FDI } \\
\text { studies in US) }\end{array}$ & $\begin{array}{l}\text { Observes changing motivations for FDI but little theoretical explanation } \\
\text { and lack of functionally oriented studies }\end{array}$ & $\begin{array}{l}\text { More narrow, function-oriented theories to advance knowledge; } \\
\text { relative performance of foreign and domestic firms as key } \\
\text { agenda }\end{array}$ \\
\hline & $\begin{array}{l}\text { Lessard, Wells } \\
\text { and Brandt } \\
\text { (1983) }\end{array}$ & $\begin{array}{l}\text { Thought Piece (JIBS } \\
\text { departmental } \\
\text { editors) }\end{array}$ & $\begin{array}{l}\text { International Finance is vibrant area of management; data availability } \\
\text { drives topics (Lessard); Significant number of manuscripts on MNE } \\
\text { (Wells); Complexity and scope of international management has not } \\
\text { facilitated the development of rigorous theoretical frameworks (Brandt) }\end{array}$ & $\begin{array}{l}\text { Positive empirical studies and normative studies (Lessard); study } \\
\text { of management processes, and on government- MNE interaction } \\
\text { (Wells); research that recognizes linkages between strategy } \\
\text { formulation, structure and global management processes } \\
\text { (Brandt). }\end{array}$ \\
\hline
\end{tabular}




\section{Sekaran}

ymsza

Hawkins

(1984)

Ricks (1985)

opinions of AIB

fellows/ scholars)

Ervin and

Survey (AIB

Toyne (1987)

气ิ Dunning

늠 (1989)

Daniels (1991) Outgoing presidential address

Presidential

address
Many of the criticisms directed at CC research apply also to single country studies. Documents challenges (e.g. sampling, instrumentation, definitional clarity, functional equivalence).

Too much reinventing the wheel, with scholars focusing on a limited range of topics; dominance of quantitative studies

IB as a field has reached a state of maturation, but research is in state of adolescence.

While empirical articles dominate JIBS, those with most impact are integrative and/or theory building in nature and provide the direction for future empirical research

Membership of AIB tends to be functionally based. Profile biased by heavy US membership. Only weak interest in comparative research.

AIB research as always been multidisciplinary, but not interdisciplinary (i.e. analyze IB issues from different, but complementary perspectives).

Much research in IB is descriptive analysis, rather than prescriptive; IB research changes little over time, with questions asked, methodologies and findings reinventing the wheel; "Hot" topics are cyclical
Accept satisficing in methods due to costs and complexities; more inductive studies; ultimate goal is to integrate our theoretical base to give solid foundation for identifying universal and particularistic management philosophies, processes and practices.

New topics that require more innovation and imagination along with rigorous approaches; multidisciplinary/ interdisciplinary, conceptual and empirical research, including normative work.

Seek a synthesis and a unifying paradigm. Key challenge to maintain relevance as grows status in scholarship.

JIBS should continue to seek integrative, theory-building articles but not neglect empirical research that provides the basis for integrative articles.

None

Advocates combination of complementary assets as the approach to IB research; Interdisciplinary, not just multidisciplinary.

Greater emphasis on prescriptive theories for relevance; retain breadth of content; more 'think pieces' to generate new ideas; explore scenarios and foreseeable futures 
Inkpen and

Beamish

(1994)

Wright and

Ricks (1994)

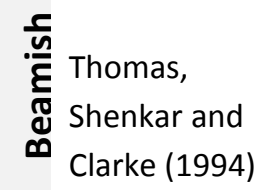

Chandy and

Williams

(1994)

Toyne and

Nigh (1997)

Caves (1998) Thought Piece

ฺั

Sullivan (1998) Empirical (Figures

in 734 JIBS

articles)

Empirical $(602$ JIBS articles)

Empirical (252

JIBS articles)

Thought Piece
Economics, finance and marketing dominated the first 20 years of JIBS. In the last 5 years, management became the most dominant

Immense growth in the size, breadth and diversity of field since 1970; geographic location of research activity now much more diverse; most research retains a narrow functional focus, but work on the interfaces and interactions among areas is emerging

IB is dominated by functional and nation-based research extended across borders and the management of multi-country operations, both focused on the firm as main unit of analysis

Substantial expansion in geographic scope of studies, but US or its major trade partners dominate; American-influenced research has become institutionalized in our mental maps, perpetuating a cycle of parochialism

Research in JIBS between 1984 and 1993 was most heavily influenced by the fields of management, economics, marketing and finance; management journal's influence exceeded influence of IB journals

Methodological challenges (e.g. controlling for the opportunities available to the firm when testing the effectiveness of its strategy choices; bias due to the study of only surviving firms; developing longitudinal data bases)

Between 1970 and 1997, JIBS articles displayed a dominance of analog reasoning and a downward trend for the comprehensiveness, connectedness and complexity in research
Those made relate to JIBS securing good articles, rather than the research itself.

Synthesis of research to date into broader, more integrative frameworks is the key challenge and holds the greatest potentia for significant new contributions; seek research that is not just

multidisciplinary, but interdisciplinary

JIBS must expand geographical horizons and define new frontiers for research

None given

More expansive, inclusive paradigm sought that is interdisciplinary, process-oriented and emphasizes multi-level interactions

Promising areas of research centre on economics questions

Rethink the logic of interpretation in ways that rejuvenate the dialectic of IB studies, and inspire ingenious and imaginative synthesis 
Buckley (2002) Thought Piece

Shenkar

Thought Piece

(2004)

Peng (2004) Thought Piece

s Buckley and

Lessard (2005)

Sullivan and

Daniels (2008)

Griffith,

Cavusgil and

Xu (2008)
Thought Piece

Thought Piece

Empirical (112

articles from 6

journals; expert

opinion)
Success of past IB research (post WW2 to 2000) was achieved by identi-

fying key empirical factors in global economy that needed explaining, and searching for tractable means of explication within a coherent theoretica framework. IB research agenda has now stalled

Landmark early studies arose from across disciplines (economics, sociology, anthropology, political science) and area studies; current calls for interdisciplinarity are limited in scope, narrowing the field of IB; narrow country focus; recent convergence to other fields (e.g. strategy)

"What determines the international success and failure of firms" has always been the guiding research question IB research of the past and present. The question exemplifies continuity, embodies broad scope, and enables novelty

IB research was initially issue-driven but by mid 1970s was increasingly theory-driven. 1980s marked by emergence of internalization theory, localization/globalization antecedents, and the transnational 'ideal'.

Primary challenge is to generate intellectual innovations that make IB's ideas relevant to a larger audience

Major themes from 1996-2006 showed persistence of mainstream IB issues; firm-related topics prevail; performance and management of the firm is an overarching theme of importance
Identify new 'big research question' and return to past basis of success

IB researchers should exploit their understanding of the rich international context and use it to make sense of business behavior; revive comparative research and local knowledge; multilevel, interdisciplinary research that copes with complexity

IB's boundaries should remain open for vibrant scholarly exchange; Continue with the fundamental research question to best exploit IB's comparative advantage (if not absolute advantage) vis-à-vis other disciplines

Suggests a refocus on one or more 'big questions', distinguishing between general theory and special theories, to defend rigour at all costs, and greater emphasis on theory-driven research.

Greater paradigmatic scope is called for; scientific and humanistic approaches should be complemented with those sensitive to nonlinear systems and non-normal probability distributions

Topics proposed for future research are more diverse, richer in terms of number of constructs, but remain enterprise and performance focused 